www.jmscr.igmpublication.org

Index Copernicus Value: 79.54

ISSN (e)-2347-176x ISSN (p) 2455-0450

crossref DOI: https://dx.doi.org/10.18535/jmscr/v7i5.166

\title{
Ocular manifestations in Rickettsial Disease in children admitted in tertiary care center in Northern India
}

\author{
Authors \\ Vijayta Gupta ${ }^{1}$, Anuj Bhatti ${ }^{*}$ \\ ${ }^{1}$ Senior Resident, Department of Ophthalmology, Government Medical College Jammu-180001 \\ ${ }^{2}$ Associate Professor, Department of Pediatrics, Government Medical College Jammu-180001 \\ *Corresponding Author \\ Anuj Bhatti \\ Associate Professor, Department of Pediatrics, Government Medical College Jammu-180001
}

\begin{abstract}
Introduction: Rickettsial disease is endemic in many parts in India. Ocular manifestation of the disease in pediatric patients is not known

Methodology: This observational study was conducted in children less than eighteen years diagnosed to have Probable rickettsial disease based upon Indian Academy of Pediatrics criteria. These children underwent visual acuity by Snellen's chart and refraction, detailed anterior chamber examination by torch and slit lamp examination, dilated biomicroscopic fundus examination. Fundus fluorescein angiography was done in cases having abnormalities on biomicrocopic fundus examination.

Results: A total of 36 children were diagnosed to have probable rickettsial disease. Best corrected visual acuity (BCVA) ranged from 6/6 to 6/60. Posterior Segment changes were seen in 24 (36\%) patients. Bilateral changes were seen in 18 children and unilateral in six (total of 42 eyes). Ocular examination showed 0.5-1+ AC reaction in 18/42 eyes, trace vitritis in 19/42 eyes, yellowish white lesions ranging from 1/2 DD to 3 DD along the arcades in all patients, suggestive of retinitis. Five eyes had less than 3 lesion and 14 eyes had more than three. Hemorrhage along with retinitis was seen in 35 eyes. Disc edema was seen in 15 eyes. Retinal vascular sheathing was seen in twelve eyes. Macular edema with star exudates was seen in 33 eyes.

Conclusion: Ocular manifestation are common in rickettsial disease. Detailed ocular examination should be done in all cases with Rickettsial disease.

Keywords: Rickttsial, posterior segment, scrub typhus.
\end{abstract}

\section{Introduction}

Rickettsial infections are now frequently being reported in many parts of India. ${ }^{(1)}$ The disease is also endemic in some parts of Jammu and Kashmir. It is zoonotic disease transmitted by to humans by the bite of contaminated arthropods, such as ticks and mites. Rickettsial diseases are classified into three major categories: the spotted fever group, the typhus group, and the scrub typhus.

The clinical symptoms include general malaise and triad of triad of fever, skin rash, and headaches. Tender regional or generalized lymphadenopathy is found in about $80-90 \%$ of cases, especially prominent in the axilla, neck and inguinal areas There are many reports on the 
systemic manifestations of Rickettsial fever from the Mediterranean region, but reports on the ophthalmic presentations of this disease are few. The existing reports describe ocular manifestation as conjunctivitis, keratitis, anterior uveitis, panuveitis, retinitis, retinal vascular occlusions, retinal vasculitis, intraretinal hemorrhages, macular edema, macular star, optic disc edema, optic neuritis, and multiple evanescent white dot syndrome-like lesions. ${ }^{(2-14)}$

Studies, evaluating the ocular manifestation in rickettsial disease from our region are few and are predominantly in adults. ${ }^{(15-20)}$ This study was undertaken with an aim to find the ocular manifestations children.

\section{Methodology}

The study was conducted in children less than 18 years admitted in Department of Pediatrics, Government Medical College Jammu over a period of one year from april 2018 to march 2019. Indian Academy of Pediatrics criteria for the diagnosis of Rickettsial disease was followed. ${ }^{(21)}$ Patients baseline demographic data, history of present illness and clinical examination was recorded in structured performa. Probable case was defined as: Suspected case having either eschar, or having rapid $(<48$ hours $)$ defervescence with anti-rickettsial therapy, or having suggestive laboratory features, or having Weil-Felix test positive with titre of 1:80 or more in OX2, OX19 or OXK. ${ }^{(21)}$ We could not define confirm case as facility for immunofluorescence assay (IFA) or immuno-peroxidase assay (IPA) was not available in our center. All positive probable cases were subjected to visual acuity by Snellen's chart and refraction, detailed anterior chamber examination by torch and slit lamp examination, dilated biomicroscopic fundus examination. Fundus fluorescein angiography was done in cases having abnormalities on biomicrocopic fundus examination. Optical coherence tomography (OCT) could not be done due to unavailability in our setup. Serial follow up examination was performed in patients with posterior segment eye changes. Descriptive statistics were used to describe baseline variables. Data analysis was done using IBM-SPSS v.20 and Microsoft Excel.

\section{Results}

A total of 36 children were diagnosed to have probable rickettsial disease. Median age of children was 11 years (IQR 9, 15). Twenty five $(69 \%)$ children were male. Finding was divided into two groups: external examination and Posterior segment.

External examination findings are depicted Table showing external manifestation of Rickettsial disease (Table 1). These manifestations occur in acute phase of disease and resolved spontaneously.

Best corrected visual acuity (BCVA) ranged from $6 / 6$ to $6 / 60$. Posterior Segment changes were seen in $24(36 \%)$ patients. Bilateral changes were seen in 18 children and unilateral in six (total of 42 eyes). These changes were seen in convalescent phase of disease. Ocular examination showed 0.5 $1+\mathrm{AC}$ reaction in 18/42 eyes, trace vitritis in 19/42 eyes, yellowish white lesions ranging from $1 / 2$ DD to 3 DD along the arcades in all patients, suggestive of retinitis. Five eyes had less than 3 lesion and 14 eyes had more than three. Hemorrhage along with retinitis was seen in 35 eyes. Disc edema was seen in 15 eyes. Retinal vascular sheathing was seen in twelve eyes. Macular edema with star exudates was seen in 33 eyes.

Fundus fluorescein angiography (FFA) showed early hypo fluorescence corresponding to retinitis patches. These turned gradually hyper fluorescent at the border of the retinitis lesions. Leakage was seen in late phase. Maculae showed no leakage. Children aged more than eight were treated with tablet Doxycycline and chidren less than eight years were treated with intravenous azithromycin. Topical steroid were used in case of AC flare/cells. Visual acuity improved in all patients with final follow up at 3 months (range 6/6 to $6 / 18)$. 
Table 1 Table showing external manifestation of Rickettsial disease

\begin{tabular}{|l|c|}
\hline Manifestation & $\mathrm{N}(\%)$ \\
\hline Conjunctival injection & $15 / 36(69.4)$ \\
\hline Subconjunctival hemorrhages & $5 / 36(13.8)$ \\
\hline Ecchymosis of eyelids & $2 / 36(5)$ \\
\hline Keratitis & $1 / 36(2.7)$ \\
\hline
\end{tabular}

\section{Discussion}

Rickettsial disease is endemic in many parts of India with reports from Jammu and Kashmir, Himachal Pradesh, Uttaranchal, Rajasthan, Assam, West Bengal, Maharashtra, Kerala, and Tamil Nadu. ${ }^{(1,22,23)}$. In a ten year study by Dasari et al, various were studied all over India. Ten out of eleven outbreak were due to scrub typhus and on was due to spotted fever. ${ }^{(1)}$

External examination finding showed no eschar or nystagmus as compared to finding by by Scheie et al. ${ }^{(17)}$ Rest of the external examination findings was similar. The posterior segment finding in our patient showed multifocal retinitis serous macular detachment with macular star exudates and optic disc involvement in the form of disc edema and disc leakage. These finding were similar to a study by Balasundaram et al that showed all 12 patients (21 eyes) presented with visual impairment ranging between (20/2000-20/30), multifocal retinitis, and 16/21 eyes had serous macular detachment with macular star exudates and optic disc involvement as evidenced by disc edema, and disc leakage on FFA was seen in 7/21 eyes. Retinal vascular sheathing adjacent to the lesions was noted in 7/21 eyes. ${ }^{(20)}$ In another similar study by Kahloun et al, rickettsial disease leading to visual loss was studies in 16 eyes of 14 patients. Retinitis was observed in 14/16 eyes, serous macular detachment in 11/14 eyes, and optic neuropathy in $7 / 16$ eyes. ${ }^{(16)}$ A study by Khairallah et al, showed less profound finding with white retinal lesions were seen in 18/60 patients, focal vessel sheathing in $5 / 60$ patients, serous retinal detachment in 3/60 patients, macular star in 2/60 patients, and optic disc edema in one patient. ${ }^{(15)}$

The finding in Rickettsial disease is due to vasculitis leading to microvascular leakage, edema, tissue hypoperfusion, and end-organ ischemic injury. ${ }^{(23)}$ Retinal injury is predominantly immune mediated with deposition of immune complexes and inflammatory cells in the retina may lead formation of white infiltrates. Diagnosis of Rickettsial disease is difficult in pediatric population and high index of suspicion is needed. The main drawback in our study was that our cases were probable rickettsial disease based upon Weil-Felix test confirmatory test like for immunofluorescence assay (IFA) or immunoperoxidase assay (IPA) could not be done due to non-availablity.

\section{Conclusion}

All patients from endemic area presenting with fever and rash with positive Weil Felix test should have detailed ocular examination including posterior segment.

\section{Funding: None \\ Conflict of interest: None}

\section{Bibliography}

1. Dasari V KP, Murhekar MV. Rickettsial disease outbreaks in India: A Review. Ann Trop Med Public Health.(7):6.

2. Alio J, Ruiz-Beltran R, Herrera I, Artola A, Ruiz-Moreno JM. Rickettsial keratitis in a case of Mediterranean spotted fever. European journal of ophthalmology. 1992;2(1):41-3.

3. Pinna A, Sotgiu M, Carta F, Zanetti S, Fadda G. Oculoglandular syndrome in Mediterranean spotted fever acquired through the eye. The British journal of ophthalmology. 1997;81(2):172.

4. Esgin H, Akata F. Bilateral multiple retinal hyperfluorescent dots in a presumed Rickettsia conorii infection. Retina (Philadelphia, Pa). 2001;21(5):535-7.

5. Pinna A, Sechi LA, Serru A, Zanetti S, Fadda G, Carta F. Endogenous panuveitis in a patient with Rickettsia conorii infection. Acta ophthalmologica Scandinavica. 2000;78(5):608-9. 
6. Mendivil A, Cuartero V. Endogenous endophthalmitis caused by Rickettsia conorii. Acta ophthalmologica Scandinavica. 1998;76(1):121-2.

7. Granel B, Serratrice J, Rey J, Conrath J, Disdier P, Weiller PJ. [Impaired visual acuity in Mediterranean boutonneuse fever]. Presse medicale (Paris, France : 1983). 2001;30(17):859.

8. Alio J, Ruiz-Beltran R, Herrero-Herrero JI, Hernandez E, Guinaldo V, Millan A. Retinal manifestations of Mediterranean spotted fever. Ophthalmologica Journal international d'ophtalmologie International journal of ophthalmology Zeitschrift fur Augenheilkunde. 1987;195(1):31-7.

9. Bloch-Michel E, Guinnepain MT, Edlinger E, Schmitt A, Herman D. [Mediterranean spotted fever: apropos of the physiopathology of uveal manifestations]. Bulletins et memoires de la Societe francaise d'ophtalmologie. 1983;95:56670.

10. Francois J. Rickettsiae in ophthalmology. Ophthalmologica Journal international d'ophtalmologie International journal of ophthalmology Zeitschrift fur Augenheilkunde. 1968;156(6):459-72.

11. Verdot S, Estavoyer JM, Prost F, Montard M. [Ocular involvement in acute phase of Mediterranean boutonneuse fever]. Bulletin des societes d'ophtalmologie de France. 1986;86(3):429-31.

12. Paufique L, Bonnet M, Lequin, Didierlaurent. [RETINAL VASCULAR THROMBOSES AND RICKETTSIOSES]. Bulletin des societes d'ophtalmologie de France. 1964;64:410-5.

13. Rivaud C, Carrica A, Chanut G, Graveline $\mathrm{J}$, Vedy J. [Early retinal manifestations of Mediterranean boutonneuse fever. Apropos of 2 cases]. Bulletin des societes d'ophtalmologie de France. 1980;80(10):961-3.
14. Castanet J, Costet C, Dubois D, Lacour JP, Ortonne JP. [Optic neuropathy in Mediterranean boutonneuse fever]. Presse medicale (Paris, France : 1983). 1988;17(9):439-40.

15. Khairallah M, Ladjimi A, Chakroun M, Messaoud R, Yahia SB, Zaouali S, et al. Posterior segment manifestations of Rickettsia conorii infection. Ophthalmology. 2004;111(3):529-34.

16. Kahloun R, Gargouri S, Abroug N, Sellami D, Ben Yahia S, Feki J, et al. Visual loss associated with rickettsial disease. Ocular immunology and inflammation. 2014;22(5):373-8.

17. Scheie HG. Ocular changes in scrub typhus; a study of 451 patients. Bulletin of the US Army Medical Department United States Army Medical Department. 1946;5:423-7.

18. Kawali A, Mahendradas P, Srinivasan P, Yadav NK, Avadhani K, Gupta K, et al. Rickettsial retinitis-an Indian perspective. Journal of ophthalmic inflammation and infection. 2015;5(1):37.

19. Bourla N, Alhalel A. [Ocular manifestations of rickettsial diseases]. Harefuah. 2005;144(11):772-3, 823.

20. Balasundaram MB, Manjunath M, Baliga G, Kapadi F. Ocular manifestations of Rickettsia conorii in South India. Indian journal of ophthalmology. 2018;66(12): 1840-4.

21. Rathi N, Kulkarni A, Yewale V. IAP Guidelines on Rickettsial Diseases in Children. Indian pediatrics. 2017;54(3) :223-9.

22. Mahajan A TaVR. Scrub typhus reemergence in Jammu. JK Sci, J Med Educ Res. 2010(12):2.

23. Rathi N, Rathi A. Rickettsial infections: Indian perspective. Indian pediatrics. 2010;47(2):157-64. 